\title{
Analysis of the Volatile Components of Five Turkish Rhododendron Species by Headspace Solid-Phase Microextraction and GC-MS (HS-SPME-GC-MS)
}

Deniz Tasdemir ${ }^{\mathrm{a},{ }^{*}}$, Betül Demirci ${ }^{\mathrm{b}}$, Fatih Demirci ${ }^{\mathrm{b}}$, Ali A. Dönmez ${ }^{\mathrm{c}}$,

K. Hüsnü Can Baser ${ }^{b}$, and Peter Rüedi ${ }^{a}$

a Institute of Organic Chemistry, University of Zurich, Winterthurerstrasse 190,

CH-8057 Zurich, Switzerland. Fax: ++41-1-6356812. E-mail: deniz@oci.unizh.ch

b Department of Pharmacognosy, Faculty of Pharmacy, Anadolu University,

TR-26470 Eskisehir, Turkey

c Department of Biology, Faculty of Science, Hacettepe University, TR-06532 Ankara, Turkey

* Author for correspondence and reprint requests

Z. Naturforsch. 58c, 797-803 (2003); received June 13/July 21, 2003

Volatile constituents of various solvent extracts ( $n$-hexane, $\mathrm{CH}_{2} \mathrm{Cl}_{2}, \mathrm{H}_{2} \mathrm{O}$ ) of 15 different organs (leaves, flowers, fruits) of five Rhododendron species (Ericaceae) growing in Turkey were trapped with headspace solid-phase microextraction (HS-SPME) technique and analyzed by GC-MS. A total of 200 compounds were detected and identified from organic extracts, while the water extracts contained only traces of few volatiles. The $\mathrm{CH}_{2} \mathrm{Cl}_{2}$ extract of the $R$. luteum flowers was found to exhibit the most diverse composition: 34 compounds were identified, with benzyl alcohol (16.6\%), limonene (14.6\%) and $p$-cymene $(8.4 \%)$ being the major compounds. The $\mathrm{CH}_{2} \mathrm{Cl}_{2}$-solubles of $R$. x sochadzeae leaves contained only phenyl ethyl alcohol. This study indicated appreciable intra-specific variations in volatile compositions within the genus. Different anatomical parts also showed altered volatile profiles. This is the first application of HS-SPME-GC-MS on the volatiles of Rhododendron species.

Key words: Rhododendron, Headspace Solid-Phase Microextraction, HS-SPME-GC-MS

\section{Introduction}

Volatile compounds are diverse in the plant kingdom and play a complex, vital role in relationships between plants and their ecological environments. Various conventional methods have been used for extracting fragrances of aromatic herbs and flowers for commercial and research purposes. Some of these methods include distillation, solvent extraction, supercritical solvent $\left(\mathrm{CO}_{2}\right)$ extraction and headspace trapping. Solid-phase microextraction (SPME) offers an alternative sampling technique for the analysis of volatile organics (Rohloff, 1999). This method is based on the adsorption of analytes on a polymeric stationery phase deposited on a fused-silica fiber via a partitioning effect between the adsorbent and the sample matrix. The adsorption is provided by immersing the precoated fiber in a liquid sample or exposing it to the headspace above a liquid or solid sample. SPME can be coupled with GC or GC-MS, where the adsorbed analytes are thermally desorbed in the injection port of the gas chromatograph with subsequent transfer to a capillary column (Bicchi et al., 2000). Although developed for the analysis of water pollutants originally, SPME has found wide application in several other fields, particularly in food chemistry and pharmaceutical analyses (Rohloff, 1999).

Rhododendron species (mountain laurel) are deciduous or evergreen shrubs commonly used as garden plants worldwide. Six Rhododendron species, one of which (R. smirnovii) is endemic, grow naturally in Turkey, especially in the northeastern Anatolia (Black Sea region) (Stevens, 1978). Some members of this genus, such as $R$. ponticum and $R$. luteum are well known for being poisonous (Baytop, 1999; Onat et al., 1991; Sütlüpınar et al., 1993). The consumption of "mad honey" (deli bal in Turkish) produced from the nectar of these plants still causes intoxications in humans in the eastern Black Sea region of Turkey (Baytop, 1999; Onat et al., 1991; Sütlüpınar et al., 1993). Serious Rhododendron poisonings are also common in livestock, particularly in sheep and goats fed with the young leaves or flowers of these species (Baytop, 1999; Puschner et al., 2001). The toxic effects 
of these plants have been attributed to grayaninetype tetracyclic diterpenes (grayanatoxins = andromedotoxins) that bind to sodium channels in cell membranes to increase the permeability of sodium ions in excitable membranes (Onat et al., 1991; Sütlüpınar et al., 1993). Interestingly, toxic Rhododendron species, particularly $R$. ponticum, are common folk medicines of the Black Sea region. $R$. ponticum is widely used as analgesic for the treatment of rheumatic or dental pain, common colds and edema, both internally and externally (Baytop, 1999). The other Turkish Rhododendron species have no reputation for being toxic. Instead, flowers of some species are eaten or their nectars are sucked by the local people (Stevens, 1978; D. T. personal observation).

The main objective of this study is the rapid identification of the volatile constituents of the solvent extracts prepared from the leaves and the flowers of two toxic Rhododendron species, $R$. ponticum and $R$. luteum, using HS-SPME coupled with GC-MS. Furthermore, 11 available organs (leaves, flowers or fruits) of three other Rhododendron plants were also studied using the same experimental conditions for comparison. Although SPME has been employed for the rapid extraction and analysis of some plant volatiles, there is no report on the application of HS-SPME on this genus. This study showed HS-SPME coupled with GC-MS to be a useful tool for the quick screening of both major and minor aromatic constituents of the organic extracts obtained from five Turkish Rhododendron species.

\section{Materials and Methods}

\section{Plant material}

Plants were collected in early July 2001 from different locations in northeast Anatolia, Turkey, and identified by one of us (A. A. D.). Identification of the specimens was based on the account of the Rhododendron in Flora of Turkey (Stevens, 1978). Voucher specimens were deposited at HUB, Department of Biology (Faculty of Science) and/or Herbarium of Department of Pharmacognosy (Faculty of Pharmacy) of Hacettepe University. Table I illustrates the names, voucher numbers, collection sites and the parts of the plants investigated.

\section{Extraction and partition}

Shadow-dried plant material (10-200 g dry weight) was ground and extracted at room temperature with $n$-hexane (extract no. 1 ), $\mathrm{CH}_{2} \mathrm{Cl}_{2}$ (extract no. 2) and $\mathrm{H}_{2} \mathrm{O}$ (extract no. 3) (three times each), respectively. Due to very low amount of material, the flowers of $R$. ponticum, $R$. luteum and $R$. ungernii were only extracted with $\mathrm{CH}_{2} \mathrm{Cl}_{2}$ and then with $\mathrm{H}_{2} \mathrm{O}$. The organic solvents were removed under low pressure at room temperature, while the water extracts were freeze-dried. Table I shows the extracts prepared from different plant samples and the abbreviations used for these extracts in the body text.

\section{Headspace-SPME}

The manual SPME device (Supelco, Bellafonte, PA, USA) with a fibre precoated of a $65 \mu \mathrm{m}$ thick layer of polydimethylsiloxane/divinylbenzene (PDMS/DVB-blue) was used for extraction of the plant volatiles. The vial containing the plant extract was sealed with parafilm. The fiber was pushed through the film layer for exposure to the headspace of the extract for $15 \mathrm{~min}$ at $50^{\circ} \mathrm{C}$. The fiber was then inserted immediately into the injection port of the GC-MS for the desorption of the adsorbed volatile compounds for analysis. This procedure was applied in triplicate.

\section{Analysis of volatile compounds}

The volatiles were analyzed by GC-MS using a Hewlett Packard GCD system. An HP-Innowax FSC column $(60 \mathrm{~m} \times 0.25 \mathrm{~mm}$ inner diameter, with $0.25 \mathrm{~mm}$ film thickness) was used with helium as carrier gas $(1 \mathrm{ml} / \mathrm{min})$. GC oven temperature was kept at $60^{\circ} \mathrm{C}$ for $10 \mathrm{~min}$ and programmed to $220{ }^{\circ} \mathrm{C}$ at a rate of $4{ }^{\circ} \mathrm{C} / \mathrm{min}$, then kept constant at $220^{\circ} \mathrm{C}$ for $10 \mathrm{~min}$ and then programmed to $240^{\circ} \mathrm{C}$ at a rate of $1^{\circ} \mathrm{C} / \mathrm{min}$, at splitless mode. The injector temperature was at $250{ }^{\circ} \mathrm{C}$. EI-mass spectra were recorded at $70 \mathrm{eV}$. Mass range was from 35 to $425 \mathrm{~m} / \mathrm{z}$.

\section{Identification of compounds}

Individual components were identified by comparison of their mass spectra using both "Medicinal and Aromatic Plant and Drug Research Centre (TBAM) Library of Essential Oil Constitu- 
ents" and "Wiley GC-MS Library". Relative percentage amounts of the separated compounds were calculated automatically from peak areas of the total ion chromatograms (TIC). n-Alkanes were used as reference points in the calculation of relative retention indices (RRI). The volatile compounds identified are listed in Table II ( $n$-hexane-solubles) and Table III $\left(\mathrm{CH}_{2} \mathrm{Cl}_{2}\right.$-solubles $)$.

\section{Results and Discussion}

The current study aimed the determination of the HS-SPME volatile profile of the flowers and the leaves of toxic $R$. ponticum and $R$. luteum that apparently attract the honeybees to collect their nectar for the production of mad honey. In addition, the leaves (R. x sochadzeae, R. ungernii and $R$. smirnovii), the flowers ( $R$. ungernii) and the unripe fruits ( $R . x$ sochadzeae) of three other Rhododendron species were also collected in their native regions (Table I). Since we were unable to perform a simultaneous on-site field sampling of living plants and subsequent GC-MS analysis, alternately we tried to extract the volatiles of the shadowdried and coarsely ground plant samples by HSSPME. This first attempt however, turned out to be unsuccessful. Minute amounts of material (especially the flowers) and the absence of sharp odor to carry out a distillation process tempted us to perform a solvent extraction. For the extraction of flowers, $\mathrm{CH}_{2} \mathrm{Cl}_{2}$ was chosen, as it is highly volatile and capable of dissolving a wide class of flavors and volatiles (Ceva-Antunes et al., 2003). All other plant material was extracted first with $n$-hexane and subsequently with $\mathrm{CH}_{2} \mathrm{Cl}_{2}$ and $\mathrm{H}_{2} \mathrm{O}$. Following the HS-SPME collection of the volatile compounds, GC-MS was used to identify the analytes in the headspace needle. $\mathrm{H}_{2} \mathrm{O}$ extracts were found to be very poor in volatiles and only traces of some organics were detected. Therefore, the results will not be discussed here. A total of 200 substances were identified in the organic extracts, which showed both qualitative and quantitative differences in a relative sense. Eighty-seven compounds in total were characterized in the $n$-hexane extracts and 115 in the $\mathrm{CH}_{2} \mathrm{Cl}_{2}$ extracts.

The headspace of the $n$-hexane extract of $R$. ponticum leaves (RPL-1) contained 14 volatile compounds, accounting $97.0 \%$ of the whole volatiles. The principal constituent of this extract was tentatively identified as a tricyclic diterpene, 5,15rosadiene $(42.8 \%)$, followed by 2 -ethyl-hexanol $(13.3 \%)$ and styrene $(10.0 \%)$. Only 8 compounds were characterized from the $\mathrm{CH}_{2} \mathrm{Cl}_{2}$ extract of the leaves (RPL-2), with 1-butanol (17.0\%) as the major component. The other major components detected in the same sample were $\gamma$-butyrolactone (13.5\%), styrene (11.8\%), benzyl alcohol (11.7\%) and $(Z)$-3-hexenol $(10.0 \%)$. The living flowers of $R$. ponticum had an attractive purplish-pink color with a slight fragrance. However, 1-methyl-2-pyrrolidone, a volatile with an unpleasant odor, was also tentatively determined to be the most abundant $(79.7 \%)$ constituent of the whole volatile fraction $(95.6 \%)$ of $R$. ponticum flowers. This may indicate that the odor is more complex, with a strong influence from the other minor volatiles that have influence on the natural scent of the flowers. Surprisingly, 1-methyl-2-pyrrolidone was completely absent in the organic extracts of the leaves.

Table I. Turkish Rhododendron species examined by HS-SPME coupled with GC-MS.

\begin{tabular}{lllll}
\hline \multicolumn{1}{c}{ Plant species } & Organ(s) used & Extracts & Voucher no & \multicolumn{1}{c}{ Collection site } \\
\hline R. ponticum L. & Leaves (RPL) & $1,2,3$ & AAD-9881 & Artvin: Damar village, Murgul, 1300 m \\
R. luteum Sweet & Flowers (RPF) & 2,3 & & \\
& Leaves (RLL) & $1,2,3$ & AAD-9882 & Artvin: Murgul, Damar village, 1300 m \\
R. x sochadzeae & Flowers (RLF) & 2,3 & & \\
Charadze \& Davlianidze & Leaves (RSoL) & $1,2,3$ & AAD-9892 & Artvin: Tiryal mountain, Taslica \\
R. ungernii Trautv. & Fruits (RSoFr) & $1,2,3$ & & $\begin{array}{l}\text { village, 2285 m } \\
\text { Leaves (RUL) }\end{array}$ \\
R. smirnovii Trautv. & Flowers (RUF) & $2,3,3$ & AAD-9880 & $\begin{array}{l}\text { Artvin: Murgul, Picea orientalis forest, } \\
\text { 1626 m }\end{array}$ \\
& Leaves (RSL) & $1,2,3$ & AAD-9889 & $\begin{array}{l}\text { Artvin: Tiryal mountain, Taslica } \\
\text { village, 2285 m }\end{array}$ \\
\hline
\end{tabular}

1: Hexane extract; 2: $\mathrm{CH}_{2} \mathrm{Cl}_{2}$ extract; $3: \mathrm{H}_{2} \mathrm{O}$ extract. 
Table II. The volatiles identified from the $n$-hexane extracts of Turkish Rhododendron species by SPME-GC-MS. RPL, R. ponticum leaves; RLL, R. luteum leaves; RSoL, $R . x$ sochadzeae leaves; RSoFr, $R$. $x$ sochadzeae fruits; RUL, $R$. ungernii leaves; RSL, $R$. smirnovii leaves; 1 , Hexane extract.

\begin{tabular}{|c|c|c|c|c|c|c|c|}
\hline RRI & Compound & RPL-1 & RLL-1 & RSoL-1 & RSoFr-1 & RUL-1 & RSL-1 \\
\hline 893 & Ethyl acetate & 4.4 & 13.3 & 4.5 & 44.8 & 4.4 & \\
\hline 1000 & Decane & & 0.8 & $\operatorname{tr}$ & 3.5 & & \\
\hline 1093 & Hexanal & & 1.3 & 4.4 & 4.5 & & \\
\hline 1100 & Undecane & 4.0 & 6.9 & 6.0 & 1.9 & & \\
\hline 1155 & 1-Butanol & 3.3 & & & & 5.8 & \\
\hline 1272 & Styrene & 10.0 & 4.3 & 7.9 & 11.7 & & \\
\hline 1348 & 6-Methyl-5-hepten-2-one & 3.2 & 11.1 & 11.9 & 3.0 & 29.4 & 21.7 \\
\hline 1360 & Hexanol & 1.5 & 1.6 & & & & \\
\hline 1391 & (Z)-3-Hexenol & 4.5 & 1.6 & 1.0 & 1.9 & 6.4 & 11.4 \\
\hline 1400 & Tetradecane & & & & & 4.8 & \\
\hline 1450 & trans-Linalool oxide (Furanoid) & & 1.5 & 4.1 & & & \\
\hline 1452 & 1-Octen-3-ol & 3.1 & 4.0 & 2.0 & & 7.9 & 9.6 \\
\hline 1478 & cis-Linalool oxide (Furanoid) & & 1.5 & & & & \\
\hline 1479 & $(E, Z)-2,4$-Heptadienal & & & 5.3 & 2.3 & & \\
\hline 1496 & 2-Ethyl-hexanol & 13.3 & 7.1 & 4.8 & 2.2 & 24.4 & 10.1 \\
\hline 1522 & 3,5-Octadien-2-one & & 1.9 & 3.1 & 4.5 & & \\
\hline 1553 & Linalool & & 2.4 & & & & \\
\hline 1602 & 6-Methyl-3,5-heptadien-2-one & 2.5 & 3.4 & 3.0 & & 7.0 & 14.6 \\
\hline 1610 & Calarene ( $=\beta$-gurjunene) & & & 7.1 & 9.0 & & \\
\hline 1641 & Methyl benzoate & & & 2.3 & & & \\
\hline 1661 & Alloaromadendrene & & & 5.1 & & & \\
\hline 1685 & Ethyl benzoate & & & 1.6 & & & \\
\hline 1706 & $\alpha$-Terpineol & 2.0 & 6.6 & & & & \\
\hline 1763 & Naphthalene & 1.9 & 1.6 & 1.2 & & & \\
\hline 1868 & (E)-Geranyl acetone & & 1.3 & 1.4 & & 4.4 & \\
\hline 1896 & Benzyl alcohol & 0.5 & 1.6 & 6.35 .4 & & & \\
\hline 1908 & Unknown* & & 0.3 & 2.4 & & & \\
\hline 1937 & Phenylethyl alcohol & & 1.2 & 1.0 & 2.4 & 5.5 & 7.4 \\
\hline 2104 & Viridiflorol & & & & & & 15.4 \\
\hline \multirow[t]{2}{*}{2232} & 5,15-Rosadiene** & 42.8 & & & & & \\
\hline & Total & 97.0 & 75.3 & 86.4 & 91.7 & 100 & 95.6 \\
\hline
\end{tabular}

RRI: Relative retention indices calculated against $n$-alkanes, \% calculated from TIC data.

tr: $\quad$ Trace $(<0.1 \%)$.

* Unknown; EIMS (70 eV): m/z (rel. int.) = 162 (6.9), 161 (13.4), 145 (96.2), 130 (14.8), 127 (15.1), 113 (27.9), $101(35.8), 74(15.4), 71(100), 59(20.1), 43(76.1)$.

** Tentative identification from Wiley.

The volatile profile of the $n$-hexane-solubles of the second toxic Rhododendron species, R. luteum, was somewhat similar to that of $R$. ponticum, with notable differences in volatile components and their relative quantities. Ethyl acetate (13.3\%), 6methyl-5-hepten-2-one (11.1\%), 2-ethyl-hexanol (7.1\%) and $\alpha$-terpineol (6.6\%) comprised the major volatile constituents of this extract (RLL-1). The $\mathrm{CH}_{2} \mathrm{Cl}_{2}$ extract of the same material (RLL2) was strongly dominated by 1-butanol $(58.7 \%)$, followed by benzyl alcohol (17.1\%) and phenylethyl alcohol $(6.7 \%)$, representing $82.5 \%$ of the volatile fraction $(88.7 \%)$. The fresh yellow flowers of $R$. luteum as well as the $\mathrm{CH}_{2} \mathrm{Cl}_{2}$ extract pre- pared therefrom were remarkably odoriferous. Indeed, the $\mathrm{CH}_{2} \mathrm{Cl}_{2}$ extract (RLF-2) showed the most diverse composition of all Rhododendron extracts investigated here. Thirty-four volatile compounds were identified, with benzyl alcohol $(16.6 \%)$, limonene $(14.6 \%)$ and $p$-cymene $(8.4 \%)$ being the major ones. The $\mathrm{H}_{2} \mathrm{O}$-soluble fraction of the flowers had also a light, delicate odor, very similar to that of $\mathrm{CH}_{2} \mathrm{Cl}_{2}$ extract. However, we were only able to detect trace amounts $(<0.1 \%)$ of limonene, 1,8-cineol and $p$-cymene in this extract (data not shown).

The volatile composition of the $n$-hexane extract of the natural hybrid, R. x sochadzeae (RSoL-1) 
Table III. The volatiles identified from the $\mathrm{CH}_{2} \mathrm{Cl}_{2}$ extracts of Turkish Rhododendron species by SPME-GC-MS. RPL, $R$. ponticum leaves; RPF, $R$. ponticum flowers; RLL, $R$. luteum leaves; RLF, $R$. luteum flowers; RSoL, $R$. $x$ sochadzeae leaves; RSoFr, $R$. x sochadzeae fruits; RUL, $R$. ungernii leaves; RUF, $R$. ungernii flowers; RSL, $R$. smirnovii leaves; $2, \mathrm{CH}_{2} \mathrm{Cl}_{2}$ extract.

\begin{tabular}{|c|c|c|c|c|c|c|c|c|c|c|}
\hline RRI & Compound & RPL-2 & RPF-2 & RLL-2 & RLF-2 & RSoL-2 & RSoFr-2 & RUL-2 & RUF-2 & RSL-2 \\
\hline 893 & Ethyl acetate & & & & & & 1.4 & 2.6 & 23.4 & 0.7 \\
\hline 1032 & $\alpha$-Pinene & & & & 0.6 & & & & & \\
\hline 1093 & Hexanal & & 3.7 & & 0.2 & & & 1.1 & 9.5 & \\
\hline 1100 & Undecane & & & & 0.4 & & & & & \\
\hline 1146 & $\delta$-2-Carene & & & & 0.6 & & & & & \\
\hline 1155 & 1-Butanol & 17.0 & & 58.7 & & & 2.5 & & & \\
\hline 1176 & $\alpha$-Phellandrene & & & & 1.2 & & & & & \\
\hline 1197 & Methyl hexanoate & & & $\operatorname{tr}$ & & & & & & 0.9 \\
\hline 1203 & Limonene & & & & 14.6 & & & & & \\
\hline 1213 & 1,8-Cineole & & & & 5.8 & & & & & \\
\hline 1255 & $\gamma$-Terpinene & & & & 0.6 & & & & & \\
\hline 1260 & 1-Pentanol & & $\operatorname{tr}$ & & & & & & & \\
\hline 1272 & Styrene & 11.8 & & & & & & & & \\
\hline 1280 & $p$-Cymene & & & & 8.4 & & & & & \\
\hline 1304 & 1-Octen-3-one & & 0.3 & & & & & & & \\
\hline 1335 & (E)-2-Heptenal & & 0.2 & & & & & & & \\
\hline 1348 & 6-Methyl-5-hepten-2-one & & & & 2.7 & & & & 17.7 & 1.4 \\
\hline 1360 & Hexanol & & & & & & 1.2 & & & \\
\hline 1391 & (Z)-3-Hexenol & 10.0 & & & & & 0.7 & & & 4.8 \\
\hline 1395 & 2-Butoxy ethanol & 2.5 & & & & & & & & \\
\hline 1399 & Methyl octanoate & & 0.2 & & & & & & & \\
\hline 1400 & Tetradecane & & & & & & 1.4 & & & \\
\hline 1400 & Nonanal & & 0.9 & & & & & & & \\
\hline 1406 & $\alpha$-Fenchone & & & & 5.4 & & & & & \\
\hline 1450 & trans-Linalool oxide (Furanoid) & & & & & & 1.9 & & & \\
\hline 1452 & 1-Octen-3-ol & & 2.3 & & & & 0.6 & $\operatorname{tr}$ & 4.8 & \\
\hline 1479 & $(E, Z)-2,4$-Heptadienal & & & & & & & 0.8 & & \\
\hline 1483 & Octyl acetate & & & & 1.4 & & & & & \\
\hline 1496 & 2-Ethyl-hexanol & & & & 3.4 & & 7.0 & 1.0 & 9.3 & \\
\hline 1500 & Methyl nonanoate & & 0.3 & & & & & & & \\
\hline 1507 & $(E, E)$-2,4-Heptadienal & & & & & & & 0.9 & & \\
\hline 1541 & Benzaldehyde & & & & 1.3 & & & 0.9 & & \\
\hline 1522 & 3,5-Octadien-2-one & & 3.9 & & & & 1.2 & & & \\
\hline 1553 & Linalool & & & & 2.3 & & & & & \\
\hline 1562 & Octanol & & & & 0.9 & & & & & \\
\hline 1595 & Isothymol methyl ether & & & & 0.4 & & & & & \\
\hline 1598 & Thymol methyl ether & & & & 0.6 & & & & & \\
\hline 1602 & 6-Methyl-3,5-heptadien-2-one & & 0.6 & & 0.8 & & 1.1 & 2.2 & & 1.9 \\
\hline 1621 & 2-Octen-1-ol & & 0.2 & & & & & & & \\
\hline 1628 & 2-(2-Ethoxyethoxy) ethanol & & & 3.3 & 1.4 & & 2.2 & 12.8 & & 7.8 \\
\hline 1651 & $\gamma$-Butyrolactone & 13.5 & & 2.9 & 0.5 & & 3.1 & 2.7 & & 6.0 \\
\hline 1663 & Phenylacetaldehyde & & & & 0.5 & & & & & \\
\hline 1678 & 1-Methyl-2-pyrrolidone* & & 79.7 & & & & & & & \\
\hline 1706 & $\alpha$-Terpineol & & & & 1.2 & & & & & \\
\hline 1715 & $(E, E)$-2,4-Nonadienal & & 0.4 & & & & & & & \\
\hline 1726 & $\gamma$-Hexalactone & 6.4 & & & & & 1.6 & 1.5 & & 3.7 \\
\hline 1751 & Carvone & & & & 1.3 & & & & & \\
\hline 1763 & Naphthalene & & & & 0.7 & & & & & \\
\hline 1779 & Methyl phenyl acetate & & 0.3 & & 3.4 & & & & & \\
\hline 1793 & Methyl nicotinate & & & & & & & & & 3.8 \\
\hline 1896 & Benzyl alcohol & 11.7 & 0.3 & 17.1 & 16.6 & & 11.6 & 9.7 & 28.9 & 13.3 \\
\hline 1908 & Unknown** & & 0.5 & & & & 3.1 & 17.6 & & 6.4 \\
\hline 1937 & Phenylethyl alcohol & 4.0 & 1.8 & 6.7 & 4.3 & 100 & 39.0 & 11.5 & 6.4 & 9.4 \\
\hline 1957 & Benzene acetonitrile & & & & 0.8 & & & & & \\
\hline 2088 & Methyl 2-methoxybenzoate & & & & 0.6 & & & & & \\
\hline 2198 & Thymol & & & & 1.3 & & & & & \\
\hline \multirow[t]{2}{*}{2308} & Cinnamyl alcohol & & & & 0.9 & & & & & \\
\hline & Total & 76.9 & 95.6 & 88.7 & 85.1 & 100 & 79.6 & 65.3 & 100 & 60.1 \\
\hline
\end{tabular}

RRI: Relative retention indices calculated against $n$-alkanes, \% calculated from TIC data.

$\begin{array}{ll}\text { tr: } & \text { Trace }(<0.1 \%) \\ * & \text { Tentative identification from Wiley. }\end{array}$

** Unknown; EIMS (70 eV): $\mathrm{m} / z$ (rel. int.) = 162 (6.9), 161 (13.4), 145 (96.2), 130 (14.8), 127 (15.1), 113 (27.9), 101 (35.8), 74 (15.4), 71 (100), 59 (20.1), 43 (76.1). 
was reminiscent of RLL-1, however the major components were replaced by 6-methyl-5-hepten2-one $(11.9 \%)$, styrene $(7.9 \%)$, calarene $(7.1 \%)$ and benzyl alcohol $(6.3 \%)$. The slight odor of the $\mathrm{CH}_{2} \mathrm{Cl}_{2}$ extract of $R$. $x$ sochadzeae leaves (RSoL2) was found to be due to phenylethyl alcohol, the only odorant detected in the headspace of this extract. RSoFr-2, the $\mathrm{CH}_{2} \mathrm{Cl}_{2}$ extract of the fruits of $R$. $x$ sochadzeae was also characterized with a high percentage of phenylethyl alcohol (39.0\%), accompanied with benzyl alcohol (11.6\%), 2-ethylhexanol $(7.0 \%)$ and 13 other minor volatiles. It is worth noting that the $n$-hexane-soluble fraction of the unripe fruits of $R$. $x$ sochadzeae (RSoFr-1) was dominated by ethyl acetate $(44.8 \%)$, a solvent never used in the present study. In order to exclude the possibility that EtOAc originates from the work-up procedure, we have analyzed the extraction solvents by GC-MS under the same conditions. No significant amount of EtOAc was detected in the solvents, indicating the natural presence of this chemical in the fruits.

6-Methyl-5-hepten-2-one (29.4\%) and 2-ethylhexanol $(24.4 \%)$ comprised the main constituents of the hexane-solubles of $R$. ungernii leaves (RUL$1)$. These two compounds, plus 8 less concentrated odorants shown in Table II represented $100 \%$ of the whole volatile material. The main constituents of the $\mathrm{CH}_{2} \mathrm{Cl}_{2}$ extract of the leaves (RUL-2) included an unknown compound (17.6\%) with low molecular weight $(\mathrm{m} / \mathrm{z}, 162)$, as well as 2-(2-ethoxyethoxy) ethanol (12.8\%), phenylethyl alcohol $(11.5 \%)$ and benzyl alcohol (9.7\%). The fresh flowers of $R$. ungernii had a light aromatic smell. Benzyl alcohol was the most predominant component $(28.9 \%)$ in the headspace of the $\mathrm{CH}_{2} \mathrm{Cl}_{2}$ extract of these flowers (RUF-2).

The $n$-hexane extract of the leaves of the endemic species, $R$. smirnovii (RSL-1), showed some similarities to that of $R$. ungernii in its volatile profile. The headspace of the former extract consisted of 8 compounds, 6 of which are common with that of RUL-1 (Table II). 6-Methyl-5-hepten-2-one
(21.7\%), viridiflorol (15.4\%) and 6-methyl-3,5heptadien-2-one $(14.6 \%)$ were the major constituents, representing the half $(51.7 \%)$ of the whole volatile fraction (95.6\%). Benzyl alcohol (13.3\%), phenylethyl alcohol (9.4\%) and 2-(2-ethoxyethoxy) ethanol $(7.8 \%)$ appeared to be main components of the $\mathrm{CH}_{2} \mathrm{Cl}_{2}$ extract of the same material (RSL-2; Table III).

Essential oils of some Rhododendron species have been investigated. Mostly terpenes such as $\alpha$ humulene, caryophyllene, limonene, $\alpha$ - or $\beta$-pinene comprise the main constituents of the essential oils (Shi, 1981; Ma et al., 1983; Doss et al., 1986; Belousov et al., 1995). In our study, with few exceptions, mostly non-terpenic hydrocarbons, alcohols, esters and ketones were present as the major components. A direct comparison with the literature data, however, is not possible. The main poisonous constituents of Rhododendron plants, grayanotoxins (andromedotoxins), were not detected in any of the extracts. These diterpenes are unstable on heating and have low vapor pressure, hence they require derivatization (TMS) before the GC analysis (Terai and Tanaka, 1993). Andromedotoxin has been isolated from the waste material in the production of Rhododendron essential oils (Belova, 1971).

Despite their dangerous potential for the public health, none of Rhododendron species growing in Turkey has been subjected to a detailed chemical investigation. This is the first systematic chemical study performed on Turkish members of this genus. Furthermore, no report has appeared on the use of HS-SPME on the volatiles of this genus so far. The current study indicated the applicability and feasibility of SPME as an alternative in quick screening of both simple and complex mixtures of organic volatiles. Also it suggested the existence of differences in the volatile composition at species level, which certainly accounts for the perceived flavor differences of flowers and other anatomical organs. 
Baytop T. (1999), Türkiye'de Bitkiler ile Tedavi, Geçmiste ve Bugün (Therapy with Medicinal Plants in Turkey, Past and Present), $2^{\text {nd }}$ ed. Nobel Tip Bas1mevi, Istanbul, Turkey, pp. 275.

Belousov M. V., Dembitsky A. D., Berezovskaya T. P., and Tikhonov V. N. (1995), Comparative characterization of essential oils of species of the genus Rhododendron, subgenus Rhododastrum (Maxim.) Drude. Rastit. Resur. 31, 41-44.

Belova N. V. (1971), Andromedotoxin and its preparation from Rhododendron. Rastit. Resur. 7, 574-576.

Bicchi C., Drigo S., and Rubiolo P. (2000), Influence on fiber coating in headspace solid-phase microextraction-gas chromatographic analysis of aromatic and medicinal plants. J. Chromatogr. A 892, 469-485.

Ceva-Antunes P. M. N., Bizzo H. R., Alves S. M., and Antunes O. A. C. (2003), Analysis of volatile compounds of Taperebá (Spondias mombin L.) and Cajá (Spondias mombin L.) by simultaneous distillation and extraction (SDE) and solid phase microextraction (SPME). J. Agric. Food Chem. 51, 1387-1392.

Doss R. P., Hatheway W. H., and Hrutfiord B. F. (1986), Composition of essential oils of some lipidote Rhododendrons. Phytochemistry 25, 1637-1640.

Ma Y., Sun S., and Wu C. (1983), GC-MS analysis of essential oil of Rhododendron dauricum. Zhiwu Xuebao 25, 563-567 (CA 100:197640).
Onat F. Y., Yegen B. C., Lawrence R., Oktay A., and Oktay S. (1991), Mad honey poisoning in man and rat. Rev. Environ. Health 9, 3-9.

Puschner B., Holstege D. M., and Lamberski N. (2001), Grayanatoxin poisoning in three goats. J. Am. Vet. Med. Assoc. 218, 573-575.

Rohloff J. (1999), Monoterpene composition of essential oil from peppermint (Mentha x piperita L.) with regard to leaf position using solid-phase microextraction and gas chromatography/mass spectrometry analysis. J. Agric. Food Chem. 47, 3782-3786.

Shi Z.-X. (1981), Gas-liquid chromatographic analysis of essential oils from four species of Rhododendron on Qinghai plateae (China). Zhongcaoyao 12, 15-17 (CA 95:156348).

Stevens P. F. (1978), Rhododendron L. In: Flora of Turkey and East Aegean Islands (Davis P. H., ed.). Edinburgh University Press, Edinburgh, UK, Vol. 6, pp. 90-94.

Sütlüpınar N., Mat A., and Satganoglu Y. (1993), Poisoning by toxic honey in Turkey. Arch. Toxicol. 67, $148-150$.

Terai T. and Tanaka S. (1993), Gas chromatographic determination of grayanotoxins. Chem. Express 8, $381-$ 384. 